\title{
Research Paper \\ A Content Analysis of the Concepts and Images of the Physical Aging Primary School Textbooks in Iran
}

\author{
Zahra Eftekhari', *Farhad Nosrati Nejad² ${ }^{2}$, Robab Sahhaf ${ }^{3}$, Nosaybeh Zanjari ${ }^{3}$
}

1. Department of Social Welfare, Student Research Committee, University of Social Welfare and Rehabilitation Sciences, Tehran, Iran. 2. Department of Social Welfare, University of Social Welfare and Rehabilitation Sciences, Tehran, Iran.

3. Iranian Research Center on Ageing, University of Social Welfare and Rehabilitation Sciences, Tehran, Iran.

Citation: Eftekhari Z, Nosrati Nejad F, Sahhaf R, Zanjari N. [A Content Analysis of the Concepts and Images of the Physical Aging Primary School Textbooks in Iran (Persian)]. Iranian Journal of Ageing. 2018; 13(2):154-167. https://doi.org/10.32598/SIJA.13.2.154

doi: : https://doi.org/10.32598/SIJA.13.2.154

Received: 27 Aug 2017 Accepted: 06 Jan 2018

Key words:

Old age, Textbooks, Content, Concept and image analysis, Elementary school, Iran

\begin{abstract}
Objectives This study has two purposes. The first purpose is to analyze the concept of old age in the textbooks of the primary schools after the Islamic Revolution (1979). The second purpose is to study the type of images used in these textbooks to depict the elderly people in physical terms.

Methods \& Materials This research is a descriptive Research to analyze the content of the books. The data is collected from a statistical population of all the primary schools' textbooks used after the Islamic Revolution. Of them, the ones which were taught in 1979, 1996, 2006, and 2015 were selected as the samples because these books were subject to change in those years. The context units were Lessens and of analysis was the contents and pictures in which the concept of old age is presented.

Results The findings of this research show that the textbooks depict aged people as those with wrinkles (52.1\%), grey or white hair (44.4\%), upright stature (57\%), and maintain good physical health (43\%). These older adults are healthy (73.2\%) and independents (72.5\%). Most of them (64.1) never used any healthcare aids, and in case of health care tools, only spectacles are depicted.

Conclusion The results showed that the textbooks depict a positive image of the physical health of the older people. The picture in the textbooks shows elders' natural status and their physical conditions in the old age. It is interesting to mention that during the first year post the Islamic Revolution, the illustrations showed the older adults as young. It's natural considering the rise of maximum life expectancy in the recent decades, and it also reflects the realities of old age.
\end{abstract}

\section{Extended Abstract}

\section{Objectives}

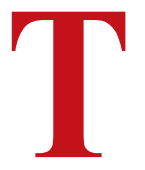

he purpose of this study was to analyze concepts and images depicting elderly in the textbooks during the initial period of post-Islamic Revolution - from 1979 to 2015. Identifying the positive and negative impact of images showing elderly from a physical point of view in the elementary school textbooks was also taken into account. It was predicted that the elderly population will increase at an ever-increasing rate. Therefore, planning for the aging population was important before the situation becomes critical. In the study by Sanagoo et al. [1], identification of the physical status of the elderly has been the most important tools to realize goals and the missions of society, and the educational system by correcting textbooks and curriculum. Hence, this was

\section{* Corresponding Author:}

Farhad Nosrati Nejad, PhD

Address: Department of Social Welfare, University of Social Welfare and Rehabilitation Sciences, Tehran, Iran.

Tel: +98 (912) 4055248

E-mail: farhad.nosrati@gmail.com 
important to set goals and missions of the society to support the elderly.

\section{Methods and Materials}

This is a descriptive research study; therefore, it has been conducted using content analysis method. The statistical population included all elementary textbooks such as Persian, Religious Education, Math, Art, Social Education, Quran, Science, Gifts of Heaven, and Thinking as well as the research from 1978 to 2015 .

Among the textbooks, those published in the years 1979, 1996, 2006, and 2015 were selected because in those years textbooks were changed. In this study, the subject was texts of the books; therefore, each lesson has been a subject. In other words, the theme was subject analysis and images related to old age. To measure the physical dimensions of aging, variables referring to the physical appearance of the elderly such as their face, hair, facial hair, stature and stance's fitness, cleanliness of their wardrobe, and clothing preferences were included. Physical appearance in terms of face implied wrinkles and folds; hair focused on the extent of the graying of hair; facial hair meant the general condition of the face, which included the degree of hair graying instances such as white or gray, salt and pepper': and the black or blond facial hair of the elderly; stature (height): straight or curved (humpy); height comparison referred to features such as being taller, having the same height, or short height; physical ability meant level of physical strengths such as high, moderate, or poor. Type of physical dependence referred to features such as being dependent or independent. Health condition meant healthy or diseased. Assistive Equipment meant relying on health tools such as spectacles, hearing aids, canes, or walker.

Data were collected using a researcher-made checklist and Jessica L. Danowski's [2] checklist. Meanwhile, this article has been confirmed by the Ethics Committee of the University of Social Welfare and Rehabilitation Sciences.

\section{Results}

The results of this study showed that aging concepts were used maximum in third and fifth-grade textbooks and minimum in the sixth and fourth-grade books. Most of the concepts were included in the Persian Book and Social Education and the least in Art and Science books. The textbooks analyzed mostly depict- ed the elderly as those with wrinkles $(52.1 \%)$, gray or white hair $(44.4 \%)$, straight posture $(57 \%)$, and high physical strength (43\%). In other words, elderly people were defined as healthy and physically independent $(72.5 \%)(73.2 \%)$. These textbooks generally $(64.1 \%)$ depicted elderly who did not use any health tools and in cases of those who used it, they only used spectacles $(14.1 \%)$.

It is worth mentioning that facial appearance of the elderly is shown with wrinkles and creases. The highest percentage of wrinkles has been observed in the textbooks used in 2015. Also, the hair and facial hair of most elderly are shown as white, and this feature is frequently repeated in the textbooks of 2015. But despite the head and face status, the stature of about 57 percent elderly people is shown as straight and the highest degree of elderly people with straight posture has been shown in the textbooks of 1996. As we move closer to 2015, stature straightness lessens. In terms of physical strength, most of the elderly are physically strong and independent. The textbooks of 2015 showed elderly population with the highest percentage of physical strength, while 2006 textbooks had the highest percentage of independent ones. From the health perspective, most of the elderly population is shown as healthy in the textbooks of 2006 and as we move closer to 2015, the percentage of healthy elderly people plummets. Noticeably, most of the elderly people had not used any health tool and those who were dependent on such tools they were mostly using glasses and canes, respectively.

\section{Conclusion}

The finding of this study is that the textbooks published in the early post-revolution years used natural images and portrayed elderly people in a positive light. It is worth mentioning here that images of the aging population in the early years are different from the recent ones, in the sense that the images of the early years of the revolution generally shows the elderly as middle-aged people or, in other words, depicted them as young. But as we moved closer to the present, these images were closer to the reality of aging population. These pictures are not only appropriate but also relates to the reality of old age in the country. This is because life expectancy increased from approximately 52 years to about 70 years in the recent years. So, it is natural that the appearance of current the aging population would be different from those in the past. 


\section{Ethical Considerations}

\section{Compliance with ethical guidelines}

This article was confirmed by the Ethics Committee of University of Social Welfare and Rehabilitation Sciences of Tehran.

\section{Funding}

This article was extracted from the master thesis of Zahra Eftekhari in the Department of Social Welfare, University of Social Welfare and Rehabilitation Sciences of Tehran.

\section{Conflict of interest}

The authors declare no conflict of interest.

\section{Acknowledgements}

We appreciate Dr. Mir-Taher Mousavi, who introduced the writers to the research organization's professors, as well as the professors of the Organization for Research and Educational Planning, Mr. Qureshi and Dr. Abolfazl Bakhtiari, who provided the opportunity to use the textbooks for this study and provided information to the authors on changes in the textbooks. 


\title{
تحليل محتواى مفاهيم و تصاوير سالمندى از بعد جسمانى در كتابهاى درسى دوره ابتدايى ايران
}

\author{
زهرا افتخارى'، "فرهاد نصرتى نزراد`م، رباب صحاف"، نسيبه زنجرى" \\ ا - كروه رفاه اجتماعى، كميثه تحقيقات دانشجويى، دانشكاه علوم بهزيستى و توانبخشى، تهران، ايران.

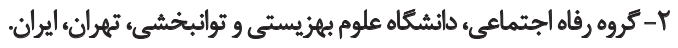

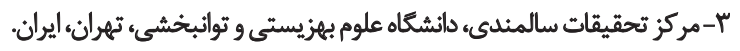

\begin{abstract}
حكSد

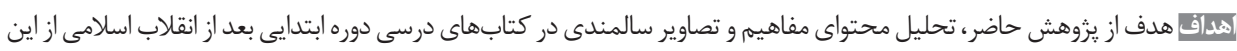

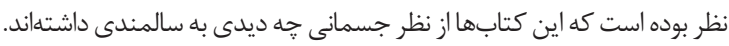

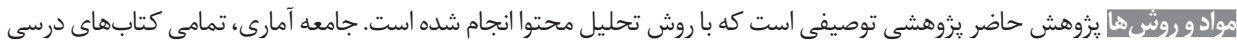

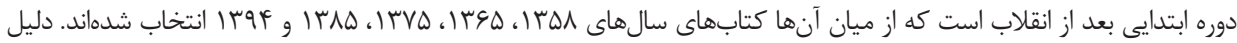

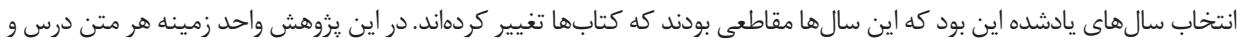

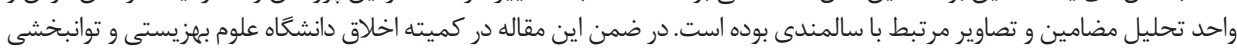
به تأييد رسيده است مضامين.

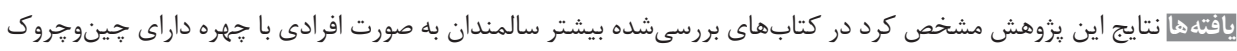

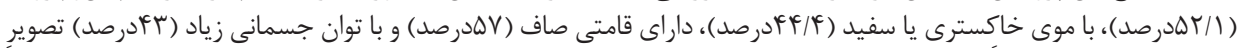

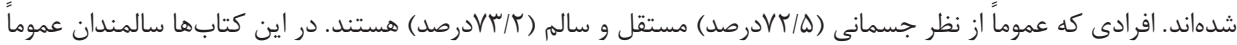

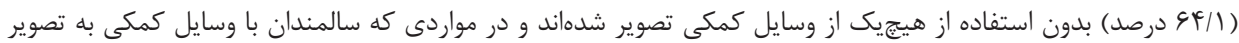

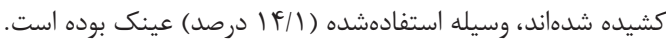

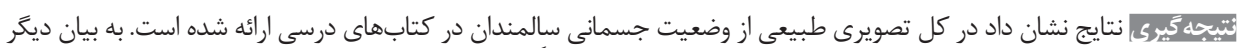

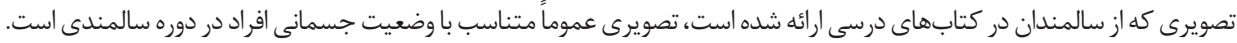

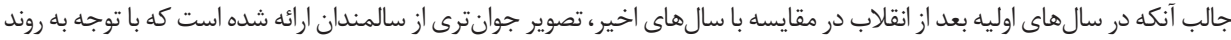

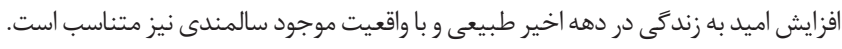

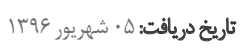

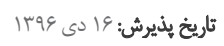

كليدواروهاء:

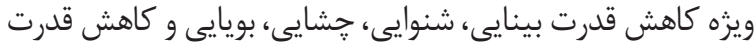

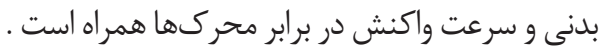

مقدمه

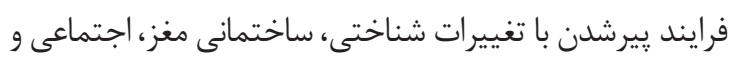

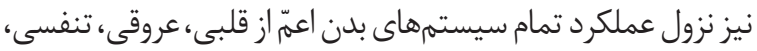

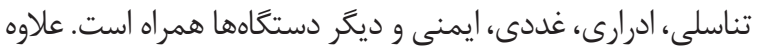

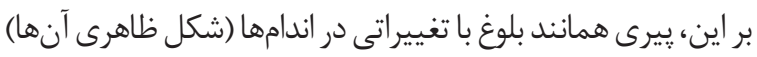

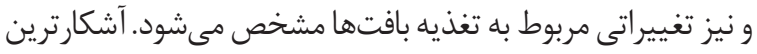

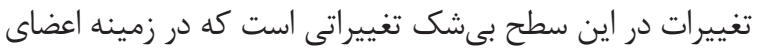

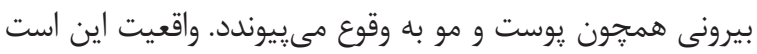

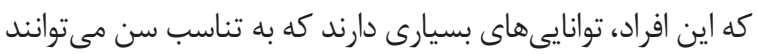

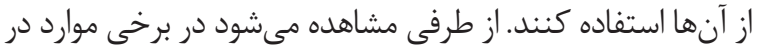

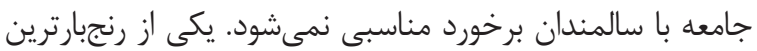

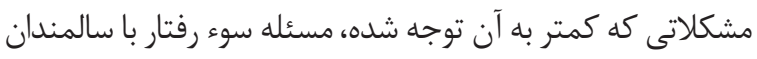

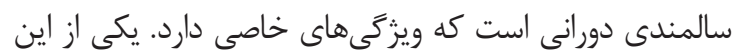

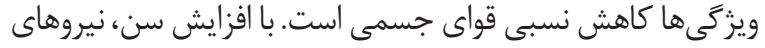

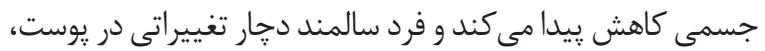

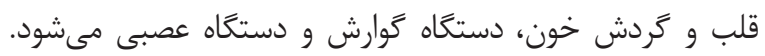

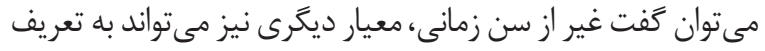

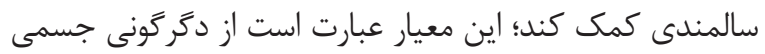

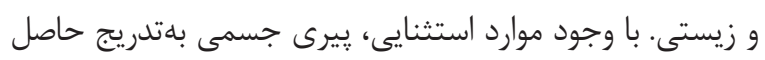

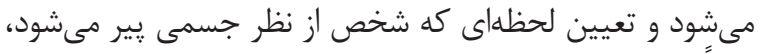

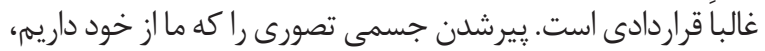

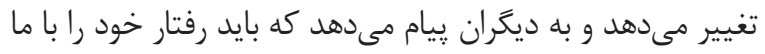

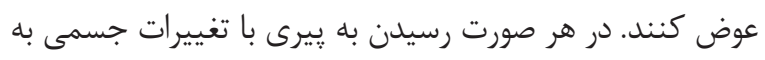


مطالعه ثناكو با عنوان (انكرش مردم نسبت به سالمندان در استان

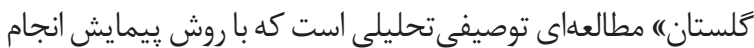

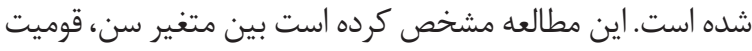

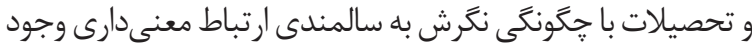

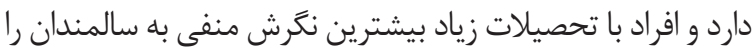

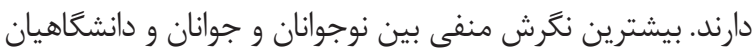

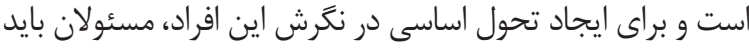

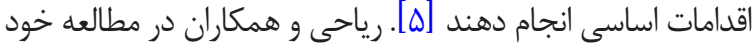

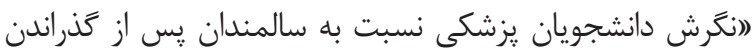

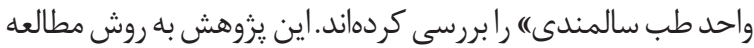

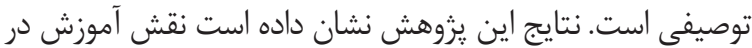

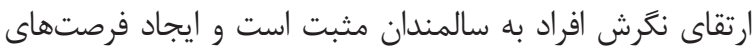

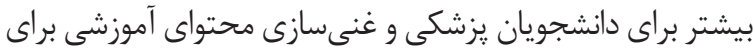

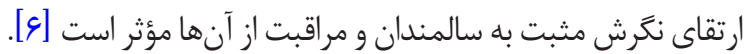
مطالعه قمرى زارع و همكاران [V] مطالعه ديخرى است كه به

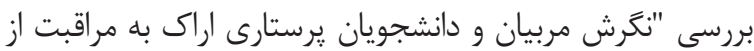

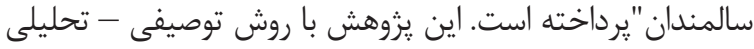

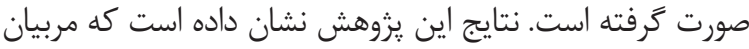

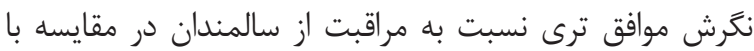

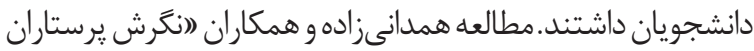

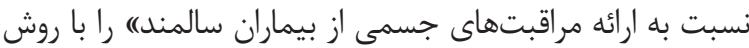

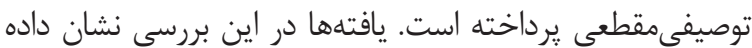

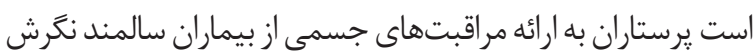

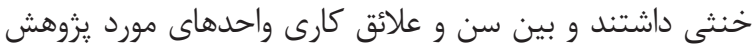

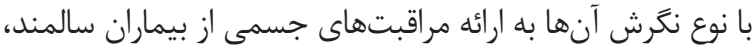

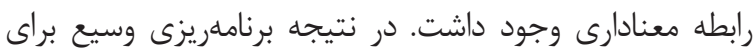

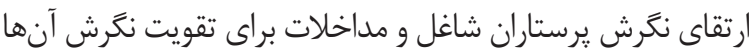

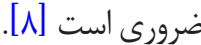
در مطالعات خارجى نيز نكرش به سالمندى بررسى شده است.

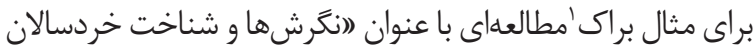

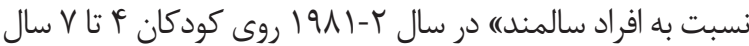

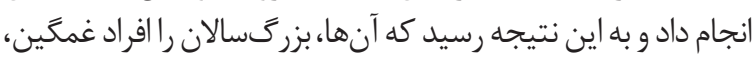

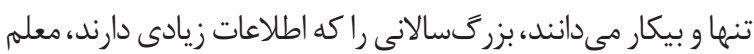

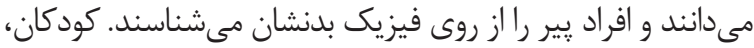

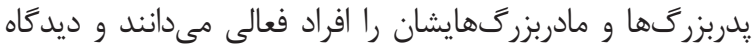

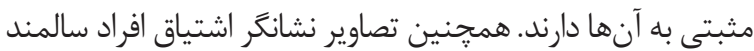

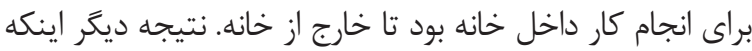

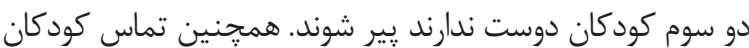

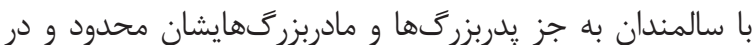

$$
\text { محيطهاى كارى و مدارس بود. }
$$

نتايج يزوهش بارت` با عنوان (برداشت جنسيتى از سالمندى:
است كه به عنوان يكى از ينهانترين اشكال خشونت در خانواده و

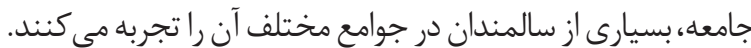

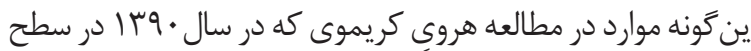

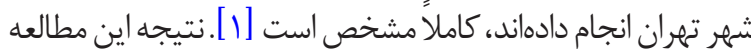

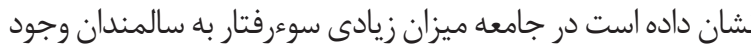

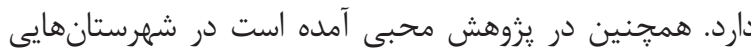

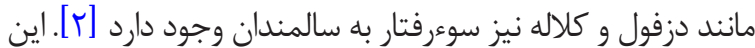

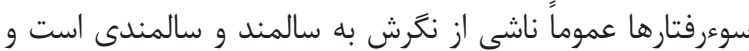

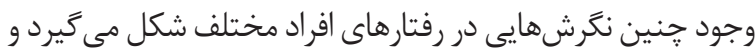

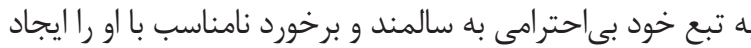

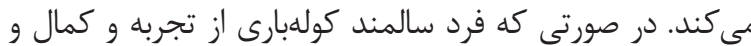
يختَى دارد و منبع فكر و انديشه براى نسل جوان است.

يكى از مسائل عصر كنونى فاصله ميان نسل جوان با سالمندان

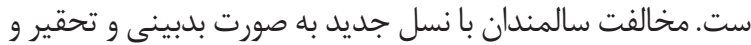

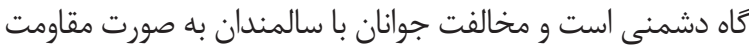

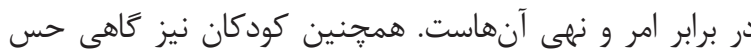

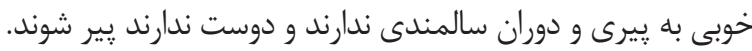

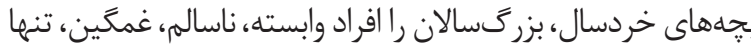

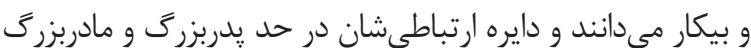

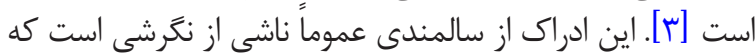

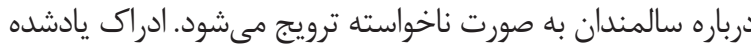

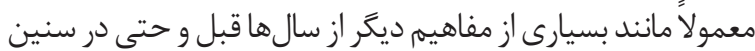

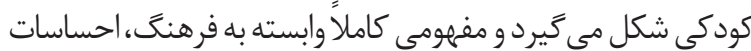

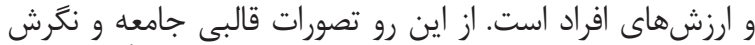

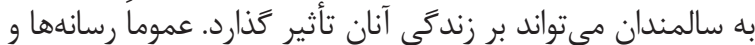

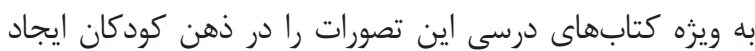

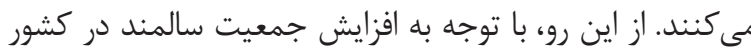

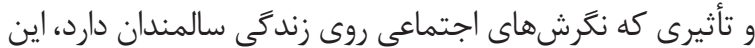

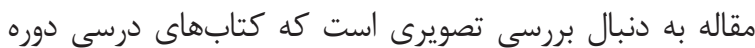
ابتدايى از ويزَگى هاى جسمانى سالمندان ارائه مي دهد.

علاوه بر تغييراتى كه در بُعد جسمانى در دوره سالمندى اتفاق

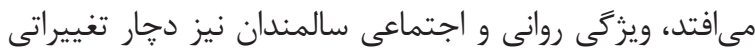

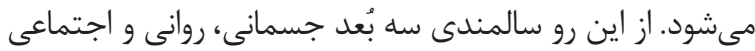

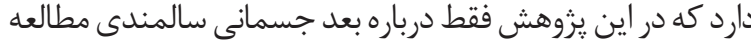

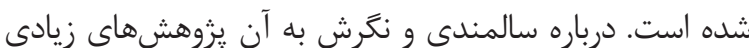

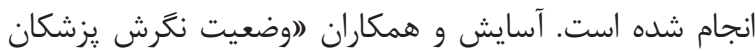

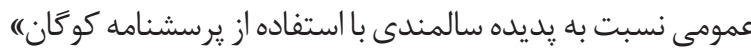

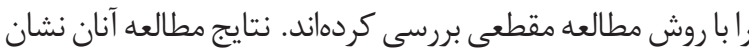

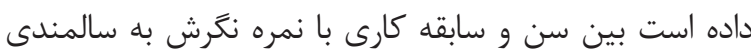

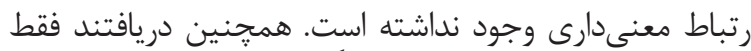

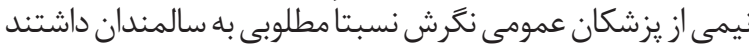

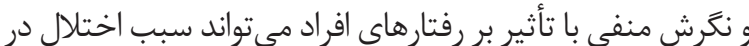

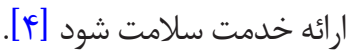




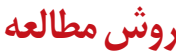

مطالعه حاضر يزروهشى توصيفى است كه با روش تحليل محتوا

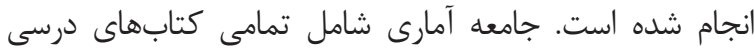

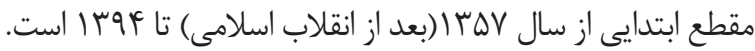

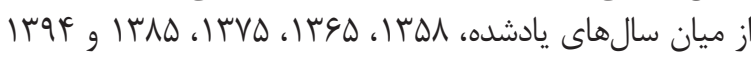

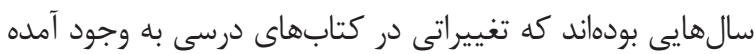

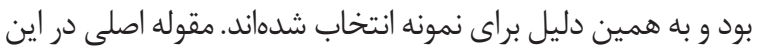

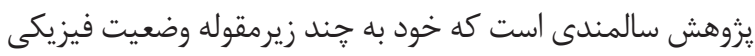

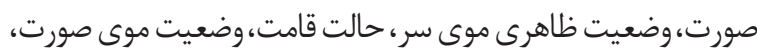

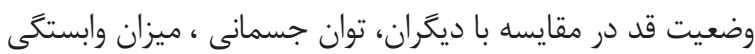

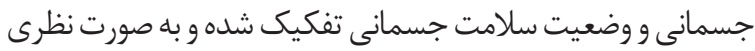

و عملياتى تعريف شده است (جدول شماره (1) ).

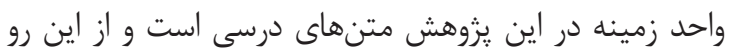

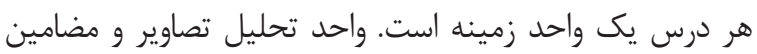

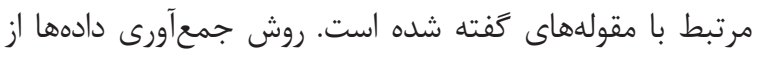

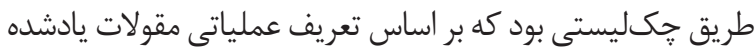

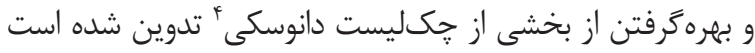

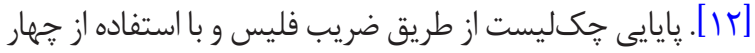

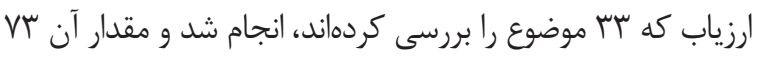

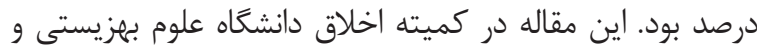
توانبخشى به تأييد رسيده است مفاله دريته

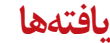

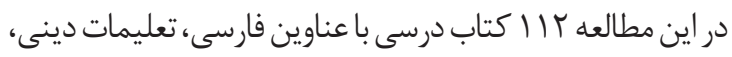

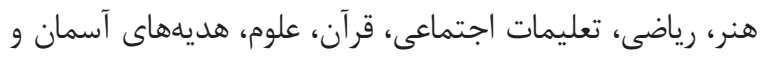

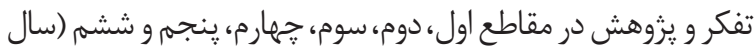

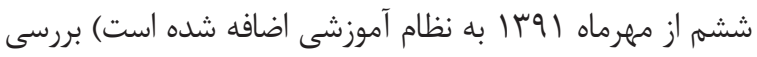

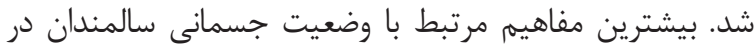

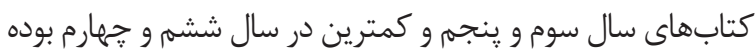

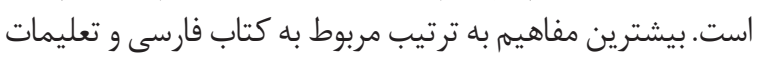

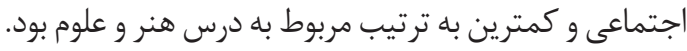

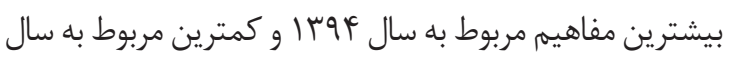

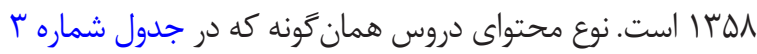

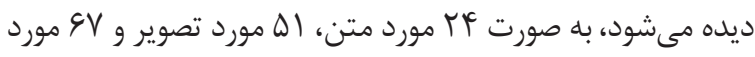

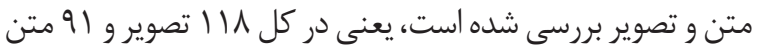
برسى شده است.

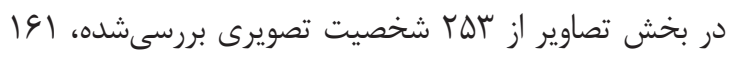

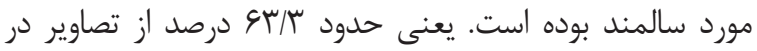

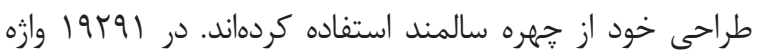

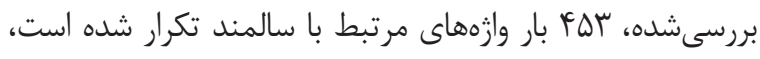

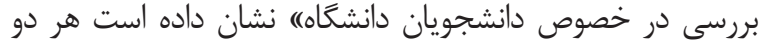

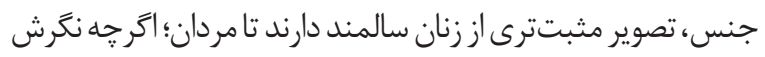

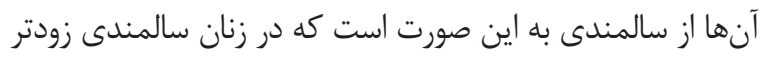

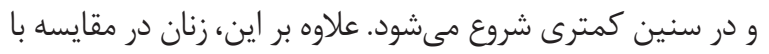

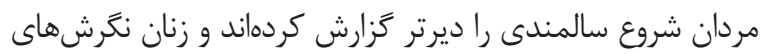

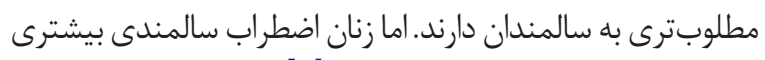

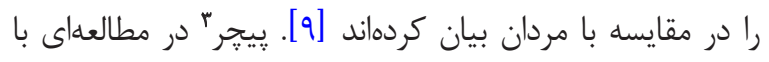

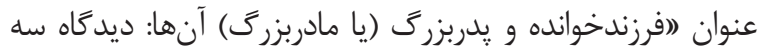

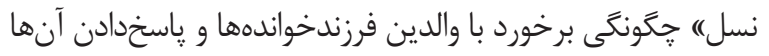

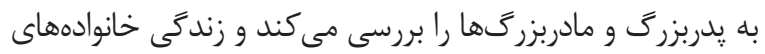

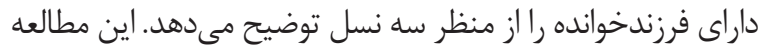

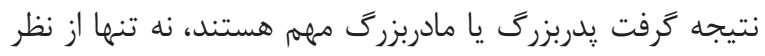

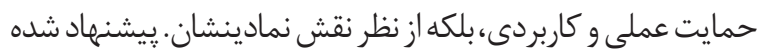

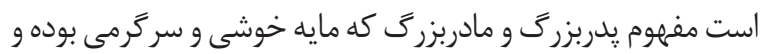

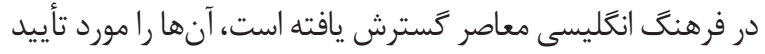

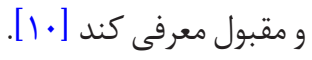

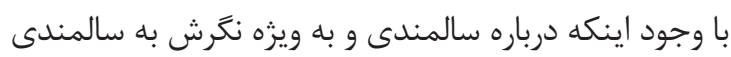

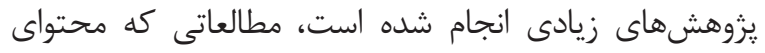

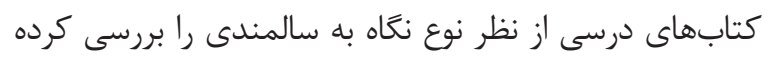

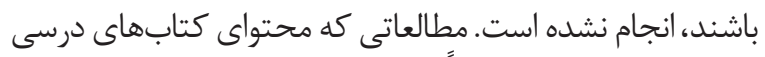

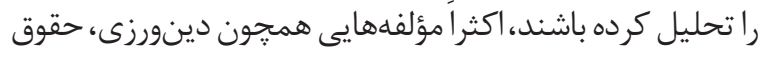

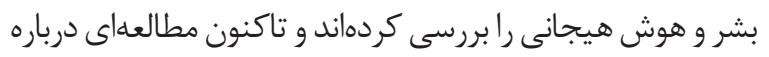

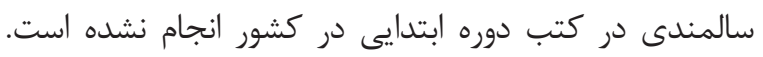

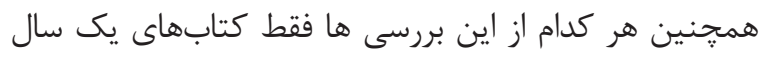

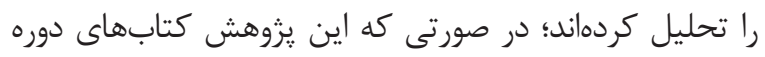

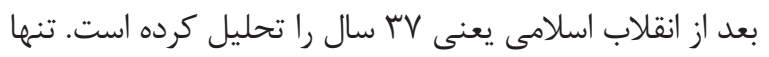

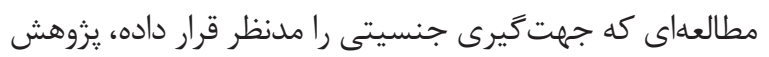

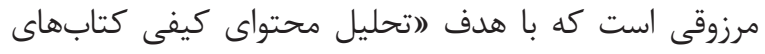

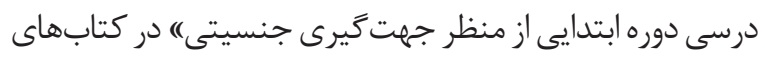

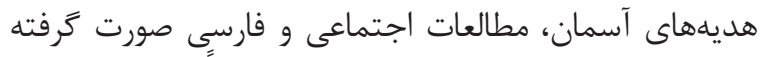

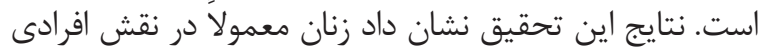

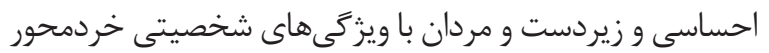

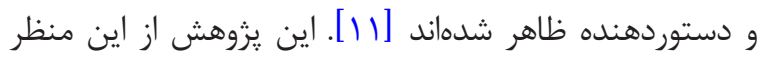

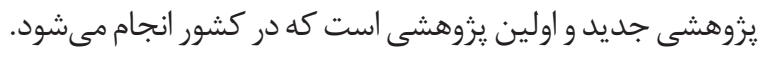

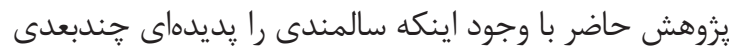

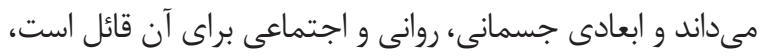

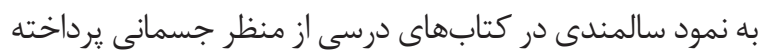

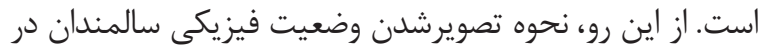

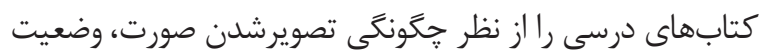

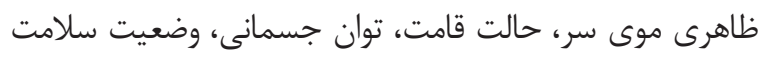
يا بيمارى و استفاده از وسايل كمكى سالمندان ران ران در كتابهان

$$
\text { درسى بررسى كرده است. }
$$


جدول ا. تعريف نظرى و عملياتى مقولات و زيرمقولهها

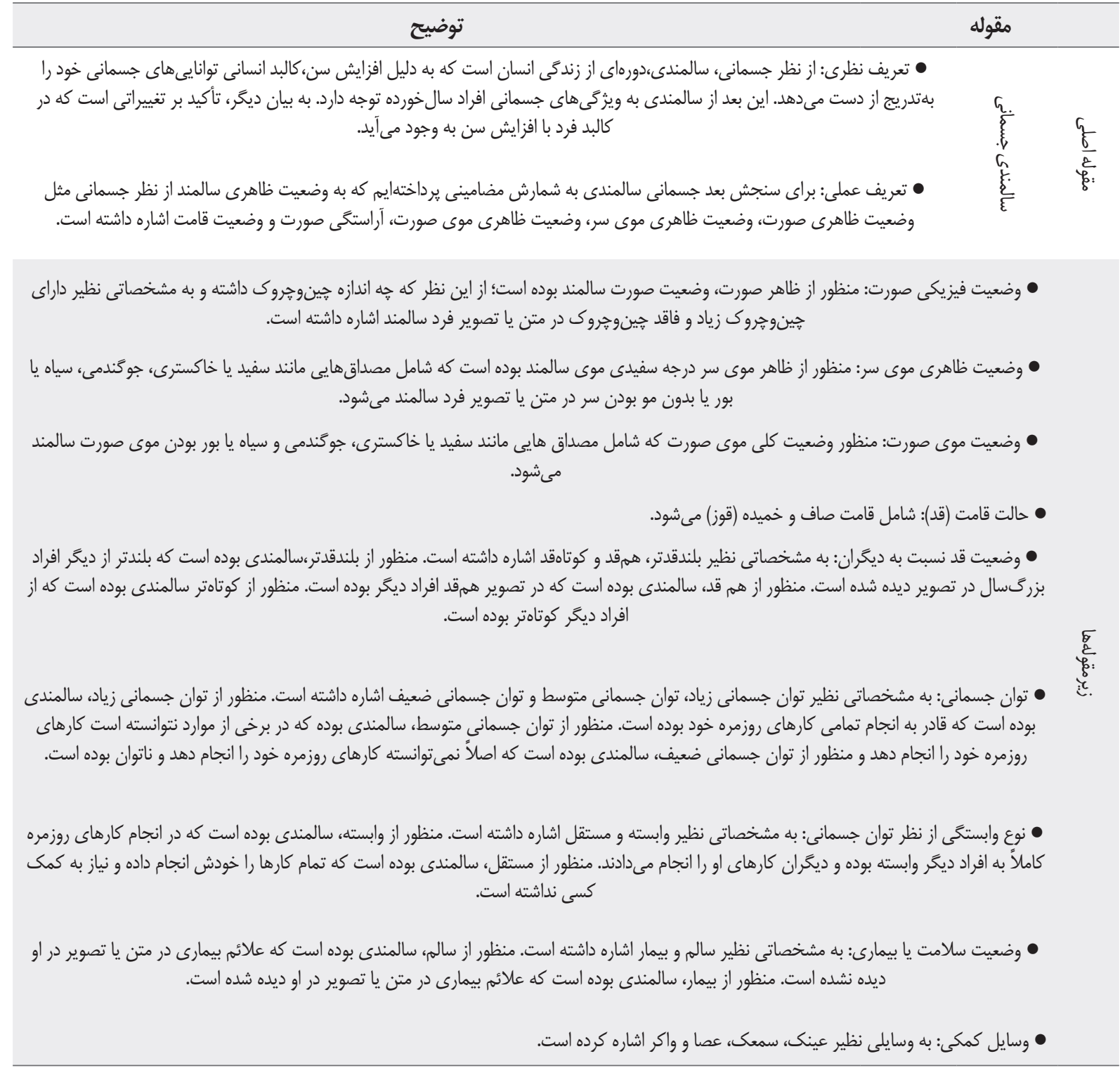

il

عينك نشان داده شدهاند. در (1/l/ (اعدرصد) از تصاوير سالمندان بدون استفاده از هيج وسيله كمكى تصوير شدهاند داند إند

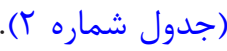
روند تغيير ات جَكَونَّى تصويرشدن وضعيت جسمانى سالمندان در كتابهاي درسى لوسيرات براى بررسى تغييراتى كه در نحوه تصويرشدن سالمندان در

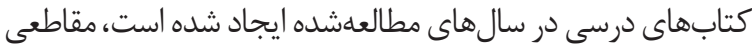
كه كتابهاى درسى تغيير كردهاند، بررسى شده داست دراس

$$
\text { تغييرات وضعيت صورت }
$$

اءر بخواهيم تغييرات جسمانى سالمندان را در جهار مقطع
يعنى تنهها س/ درصد از وازمهاى مرتبط با سالمندان در متن استفاده

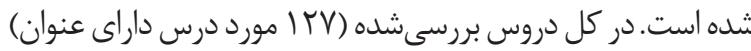

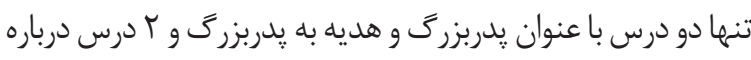

$$
\text { والدين ديده شد. }
$$

تصوير وضعيت سالمندان در كتابهاى درسى از منظر جسمانى در كتابهاى بررسىشده بيشتر سالمندان افرادى با باكي

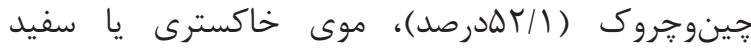
( تصوير شدهاند.

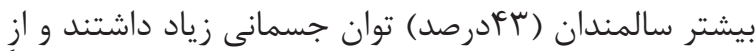

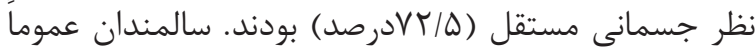

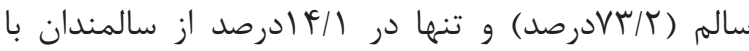


جدول ז. بررسى جَكونكى وضعيت جسمانى سالمندان در كتابهاى درسى

\begin{tabular}{|c|c|c|c|c|}
\hline \multicolumn{5}{|c|}{ وضعيت جسمانى } \\
\hline جمع كل/درصد & نامشخص" & فاقد جِينوجروكى & داراى جينوجروى & وضعيت فيزيكى صورت \\
\hline $\operatorname{let}(1+\cdot)$ & $T V(19)$ & $F \mid(T \Lambda)$ & $V^{f}(\Delta T / I)$ & تعداد (درصد) \\
\hline
\end{tabular}

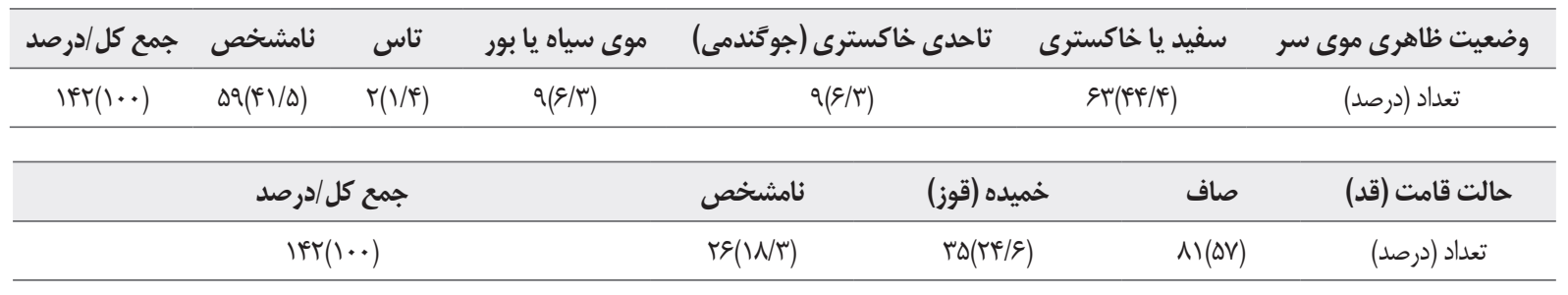

\begin{tabular}{|c|c|c|c|c|c|}
\hline جمع كل/درصد & نامشخص & توان جسمانى ضعيف (ناتوان) & توان جسمانى متوسط & توان جسمانى بالا & توان جسمانى \\
\hline $\operatorname{ler}(1 \cdots)$ & $r \cdot(r / /)$ & $1 \cdot(\mathrm{V})$ & $F \backslash(T \wedge / q)$ & SI(אT) & تعداد (درصد) \\
\hline
\end{tabular}

\begin{tabular}{|c|c|c|c|c|}
\hline جمع كل/درصد & نامشخص & 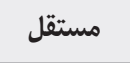 & وابسته ( ناتوان يا كم توان) & نوع وابستكى از نظر توان جسمانى \\
\hline $\operatorname{IfT}(1 \cdots)$ & $r(I r / \Lambda)$ & $1 . r(V Y / \Delta)$ & $M(I T / V)$ & تعداد (درصد) \\
\hline
\end{tabular}

\begin{tabular}{|c|c|c|c|c|}
\hline جمع كل/درصد & نامشخص & بيمار ( نوع بيمارى) & سالم & وضعيت سلامت يا بيمارى \\
\hline $\operatorname{ler}(1 \cdots)$ & $r V(19)$ & $11(V / V)$ & $1 \cdot r(V K / T)$ & تعداد (درصد) \\
\hline
\end{tabular}

\begin{tabular}{|c|c|c|c|c|c|c|c|}
\hline جمع كل | درصد & 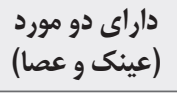 & هيجكدام & نامشخص & عصا & سمعك & عينك & وسايل كمكى \\
\hline $\operatorname{ler}(1 \cdots)$ & $\Delta(\omega / \Delta)$ & $91(95 / 1)$ & $1 \%(q / T)$ & $I r(N / \Delta)$ & $I(\cdot / V)$ & $r \cdot(1 F / 1)$ & تعداد (درصد) \\
\hline
\end{tabular}

$$
\text { تغيير ات مربوط به توان جسمانى }
$$

همانطور كه در جدول شماره 9 نشان داده شده است، هرجه

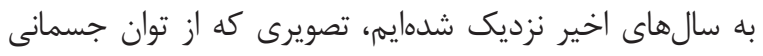

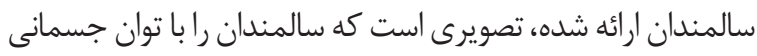

$$
\text { زياد ترسيم كرده است. }
$$

بر اساس جدول شماره V تصويرى كه از وضعيت وابستگى جسمانى

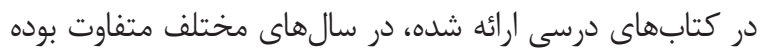

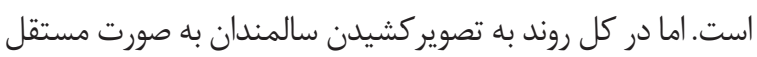

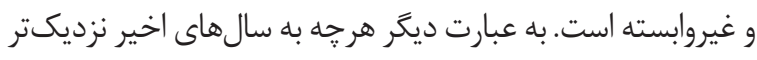

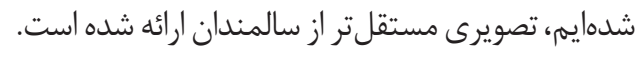

$$
\text { تغيير ات از نظر وضعيت سالامت يا بيمارى }
$$

بر اساس جدول شماره ^، مىتوان بيان كرد بيماربودن

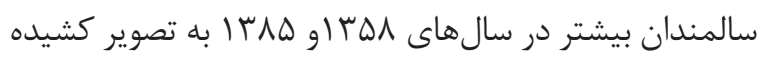

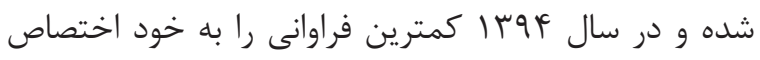

ذكرشده بررسى كنيم، مىتوان ابراز كرد با توجه به جدول

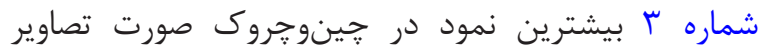

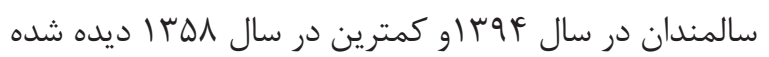
است. به دليل اينكه كتابهاى متأخرتر تصويرها را واضحتر

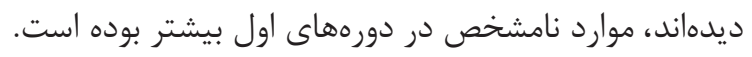

$$
\text { تغيير ات وضعيت موى سر }
$$

روند تغييرات ظاهرى موى سر بر اساس جدول شماره أ نشاندهنده

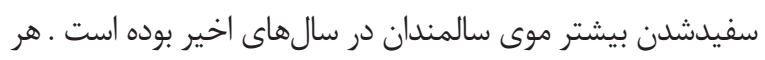

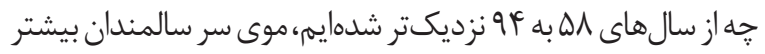
سفيد تصوير شده است. تغيير ات حالت قد

درباره حالت قد سالمندان بر اساس جدول شماره ه هان

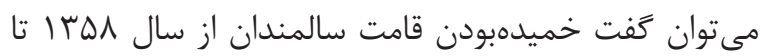
سال ع سا بيشتر به تصوير كشيده شده است. 


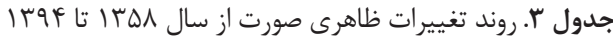

\begin{tabular}{|c|c|c|c|c|}
\hline \multicolumn{4}{|c|}{ وضعيت ظاهرى صورت/ فراوانى (درصد) } & \multirow{2}{*}{ سال } \\
\hline كل & نامشخص & فاقد جِين و جروك & داراى جِين و گروكى & \\
\hline$M(1 \cdots)$ & $V($ ऍ $/ / q)$ & $T(T / T)$ & $V($ ( $N / q)$ & $\mid r \Delta \alpha$ \\
\hline$r q(1 .)$. & $\Lambda(\Gamma V / \varphi)$ & $\Lambda(\Gamma V / \varphi)$ & $\mid \pi(\kappa</ \Lambda)$ & IrVa \\
\hline$r \cdot(1+)$. & $F(1 \mu / \mu)$ & W(س & $10(\Delta \cdot)$ & DAN \\
\hline $\operatorname{so}(1 \cdots)$ & $\Lambda(I N / \Gamma)$ & $M(T V / V)$ & rq(६.) & Irq4 \\
\hline
\end{tabular}

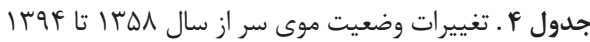

\begin{tabular}{|c|c|c|c|c|c|c|c|}
\hline \multicolumn{7}{|c|}{ وضعيت ظاهرى موى سر / فراوانى (درصد) } & \multirow{3}{*}{ سال } \\
\hline \multicolumn{2}{|c|}{ كل } & نامشخص & 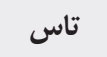 & بور يا سياه & جوكَندمى & سفيد & \\
\hline$M(1 \cdots)$ & فراوانى & $11(9) / 1)$ & $r(1) / 1)$ & $r(1) / 1)$ & $-(-)$ & $\Gamma(\mid \xi / V)$ & \\
\hline$r q(1 \cdots)$ & فراوانى & $\mid r(F \backslash / F)$ & $-(-)$ & $r(1 \cdot / \mu)$ & $r(q / 9)$ & $\mid r(\mathbb{F} \mid / \mathbb{F})$ & ITVa \\
\hline$r \cdot(1 \cdot \cdot)$ & 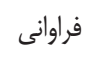 & $\operatorname{Ir}\left(\mathbb{F}^{*}\right)$ & $-(-)$ & $I(\mu / \mu)$ & $r(\xi / V)$ & $1 Q(\Delta \cdot)$ & 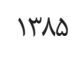 \\
\hline $9 \Delta(1 \cdots)$ & فراوانى & $r \in(r \& / q)$ & $-(-)$ & $r(\mathcal{c} / \varepsilon)$ & $\Delta(V / V)$ & $\mu(\Delta \cdot / \Lambda)$ & Irqf \\
\hline
\end{tabular}

旔

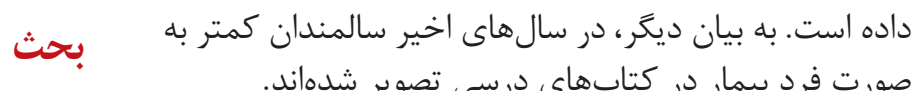

نتايج اين يزروهش نشان داد آنجه از وضعيت جسمانى سالمندان

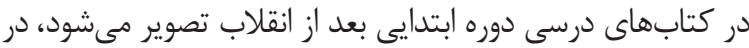

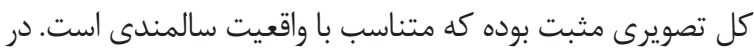

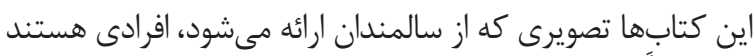

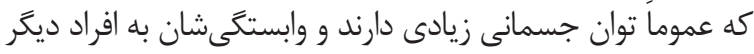

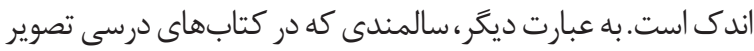

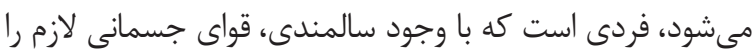

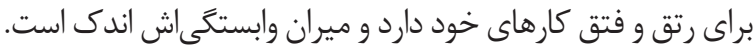
اين در حالى است كه تصويرى كه از وضعيت ظاهرى سالمند دوند نشان

تغيير ات مربوط به استفاده از وسايل كمكى

همانطور كه در جدول شماره 9 نشان داده شده است، در كتابهاى درسى در همه سالها عموماً سالمندان بدون دماره

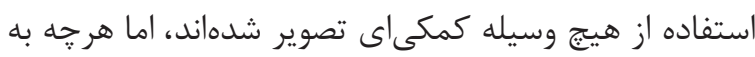

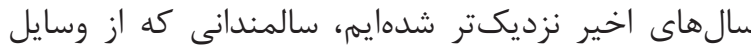

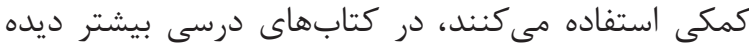
مى شوند.

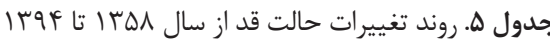

\begin{tabular}{|c|c|c|c|c|}
\hline \multicolumn{4}{|c|}{ حالت قد/ فراوانى (درصد) } & \multirow{2}{*}{ سال } \\
\hline كل & نامشخص & خميده & صاف & \\
\hline$M(1 \cdots)$ & $1 \cdot(\Delta \omega / \varepsilon)$ & $I(\Delta / \mathcal{Q})$ & $V($ r $/ / q)$ & $1 \pi \Delta \lambda$ \\
\hline$r q(1 .)$. & $V(\Gamma \varphi / I)$ & $F(I N / \Lambda)$ & $\mid N(E T / I)$ & ITVD \\
\hline$r \cdot(1 \cdot \cdot)$ & $F(I N / T)$ & $\wedge(Y \& / V)$ & $M(\varepsilon \cdot)$ & \\
\hline $9 D(1 \cdots)$ & $\Delta(V / V)$ & $r r(r / \Lambda)$ & $\Gamma \wedge(\Delta \wedge / \Delta)$ & Irq4 \\
\hline
\end{tabular}

地 


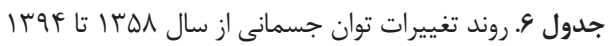

\begin{tabular}{|c|c|c|c|c|c|}
\hline \multicolumn{5}{|c|}{ توان جسمانى / فراوانى (درصد) } & \multirow{2}{*}{ 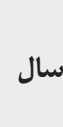 } \\
\hline كل & 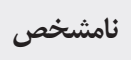 & ضعيف & متوسط & بالا & \\
\hline$M(\mid \cdots)$ & $V($ YN/q) & $r(19 / V)$ & $I(\Delta / \xi)$ & $\varepsilon(\mu / \mu)$ & $\| \pi \Delta \wedge$ \\
\hline$r q(1 \cdots)$ & $V(Y \Gamma / I)$ & $r(\xi / q)$ & $\Lambda(\ulcorner V / \&)$ & $\mid r(F \mid / F)$ & ITV \\
\hline$r \cdot(1 \cdot \cdot)$ & $r(\varepsilon / V)$ & $r(\xi / V)$ & 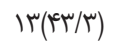 & (T) & טגו \\
\hline$s \Delta() \cdots)$ & $\| \mu\left(r_{\cdot}\right)$ & $\mu(\mathcal{F} / \varepsilon)$ & $19(r q / r)$ & $r \cdot(\kappa \& / T)$ & Irqf \\
\hline
\end{tabular}

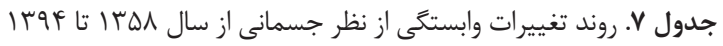

\begin{tabular}{|c|c|c|c|c|}
\hline \multicolumn{4}{|c|}{ وابستَّى از نظرجسمانى فراوانى (درصد) } & \multirow{2}{*}{ سال } \\
\hline كل & نامشخص & مستقل & وابسته & \\
\hline$M(1 \cdots)$ & $\Lambda(F \varphi / F)$ & $\varepsilon(\Gamma / \mu / \mu)$ & $F(T / T)$ & $\mid r \Delta \Lambda$ \\
\hline$r q(1 .)$. & $F(I N / \Lambda)$ & $r r(V Q / q)$ & $\Gamma(1 \cdot / \mu)$ & ITVD \\
\hline$r \cdot(1 \cdot \cdot)$ & $1(\Gamma / \mu)$ & $\operatorname{TF}(\Lambda \cdot)$ & $\Delta(1 \xi / V)$ & טגו \\
\hline $9 \Delta(1 \cdot \cdot)$ & $\Lambda(I T / T)$ & $\Delta \backslash(Y \wedge / \Delta)$ & $q(q / T)$ & 1rq4 \\
\hline
\end{tabular}

به نظر مىرسد اين تصوير با واقعيت سالمندى در كشور تناسب

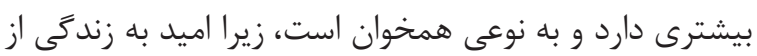

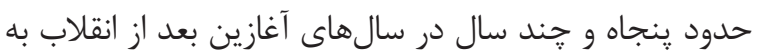

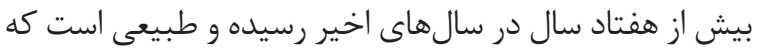

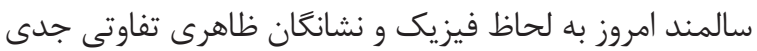

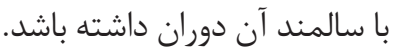

در كل نتايج اين يزوهش نشان مىدهد ريشه سويههاى

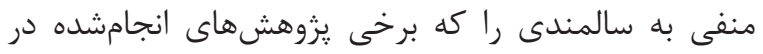

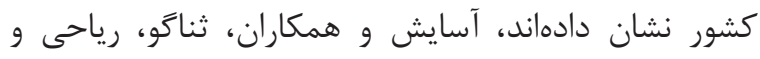

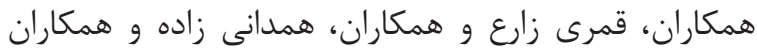

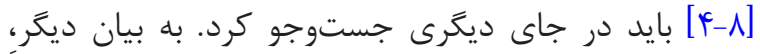

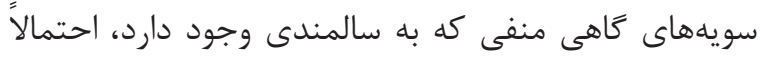

مى عهد، فردى است كه نشانگان سال خوردگى را دارد؛ يعنى اين افراد

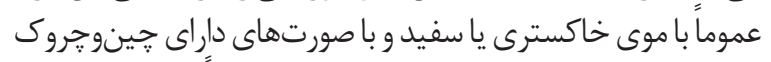

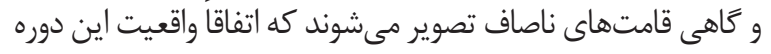

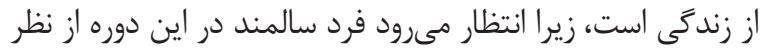

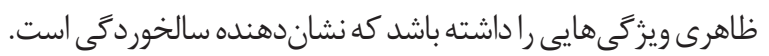
نكته جالب توجه در اين :زثوهش آن است كه تصويرى كه

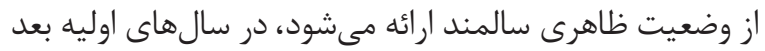

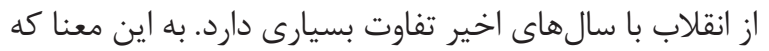

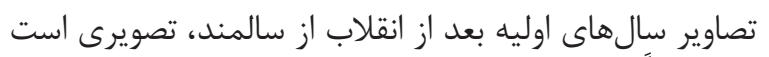

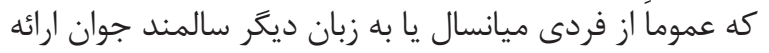

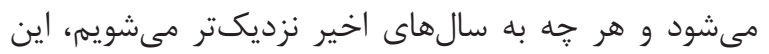

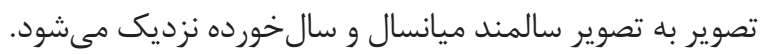

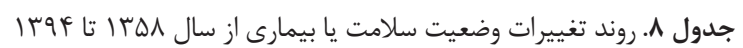

\begin{tabular}{|c|c|c|c|c|}
\hline \multicolumn{4}{|c|}{ وضعيت سلامت يا بيمارى / فراوانى (درصد) } & \multirow{2}{*}{ سال } \\
\hline كل & نامشخص & بيمار & سالم & \\
\hline$M(1 \cdots)$ & $q(\Delta \cdot)$ & $r(1) / 1)$ & $V(r \wedge / q)$ & $\| \pi \Delta \Lambda$ \\
\hline$r q(1 . \cdot)$ & $r(1 \cdot / \mu)$ & $r(\varepsilon / 9)$ & $M{ }^{E}(\Lambda T / \Lambda)$ & Irva \\
\hline$r \cdot(1 \cdots)$ & $1(r / \mu)$ & $r(1 \cdot)$ & $r \varepsilon(\Lambda \& / V)$ & נNאו \\
\hline$\varepsilon \Delta(1 \cdots)$ & $\| f(r \mid / \Delta)$ & $r(\varepsilon / r)$ & $\mathcal{F}(V T / T)$ & 1494 \\
\hline
\end{tabular}




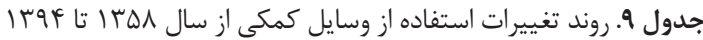

\begin{tabular}{|c|c|c|c|c|c|}
\hline \multicolumn{5}{|c|}{ وسايل كمكى / فراوانى (درصد) } & \multirow{2}{*}{ 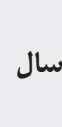 } \\
\hline كل & هيجِكدام & واكر يا ويلجِ & عينك & عصا & \\
\hline$M(1 \cdots)$ & $19(\mathcal{N} / 9)$ & $-(-)$ & $-(-)$ & $r(1) / 1)$ & $\| \pi \Delta \Lambda$ \\
\hline$r q(1 .)$. & $r F(\Lambda r / \Lambda)$ & $-(-)$ & $r(1 \cdot / r)$ & $r(\xi / q)$ & ITVa \\
\hline$r \cdot(1 \cdot \cdot)$ & $r \Psi(V \& / V)$ & $-(-)$ & $F(I r / r)$ & $r(1 \cdot)$ & هוזו \\
\hline$V \pi(1 . \cdot)$ & $F \backslash(\Delta \& / T)$ & $1\left(1 / N^{\mathbb{E}}\right)$ & $19(K \varepsilon)$ & $\mid r(\mid \& / \mathbb{F})$ & Irqq \\
\hline
\end{tabular}

كامل كتابهاى درسى، در دسترسنبودن بانك اطلاعات اينترنتى

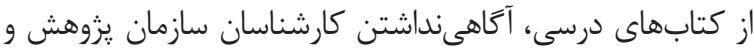

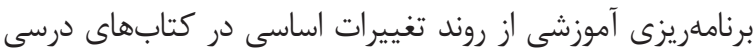

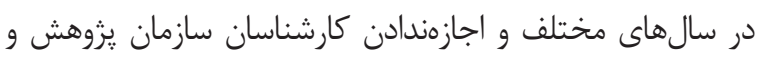

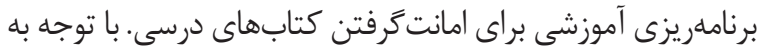

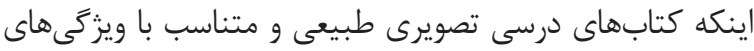

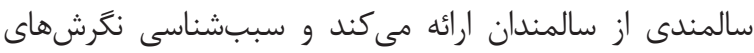

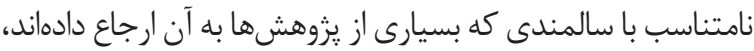

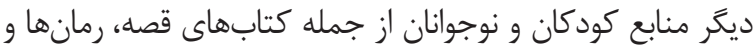

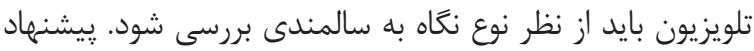

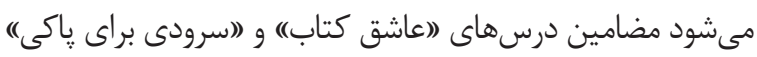

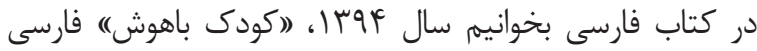

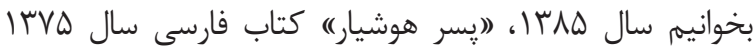
متناسب باشأن اجتماعى سالمندان بازنخرى شوند.

$$
\text { تشكر و قدردانى }
$$

در يايان از استاد فرزانه و فرهيخته جناب آقاى دكتر ميرطاهر موسوى كه نويسند

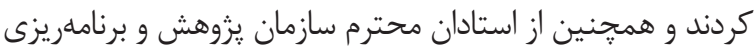

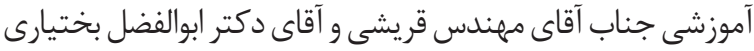

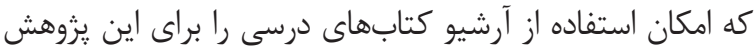

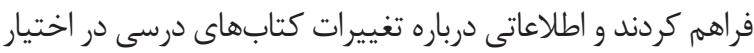

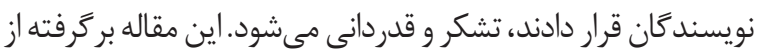
يايان نامه كارشناسى ارشد زهرا افتخارى است.

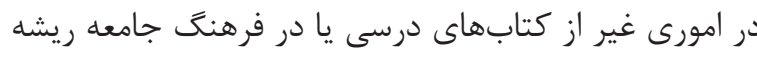

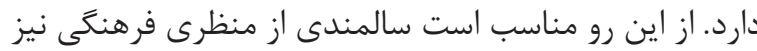
مطاله شود.

\section{نتيجه كَيرى نهايى}

به طور كلى تصويرى كه از سالمند در كتابهاى درسى ارائه

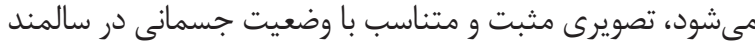

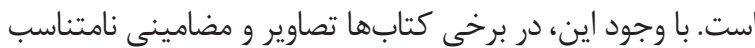

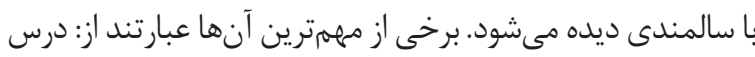

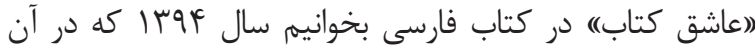

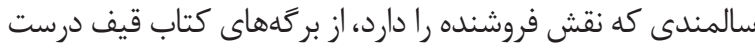

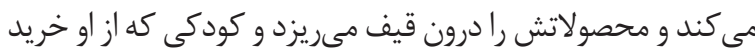

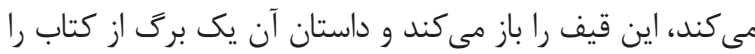

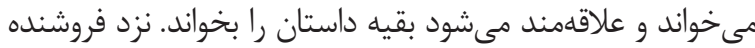

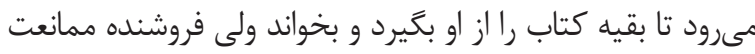
مى كند.

در همان كتاب در درسى با عنوان (اسرودى براى ڤاكى)،

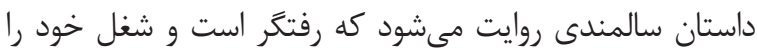

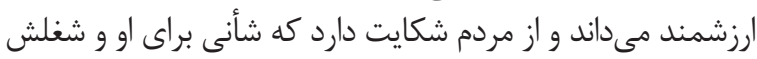

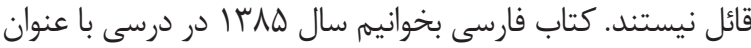

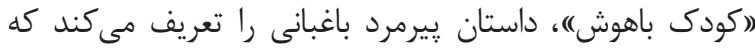

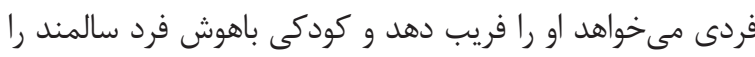

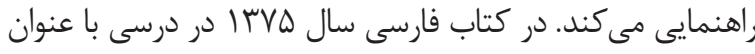

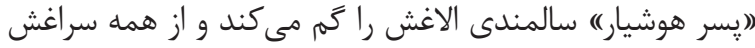

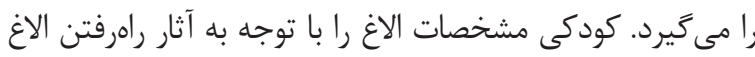

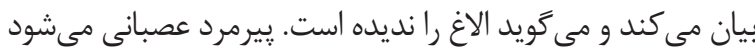

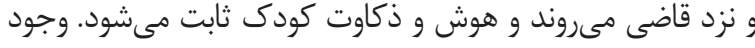

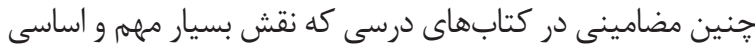

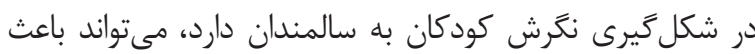

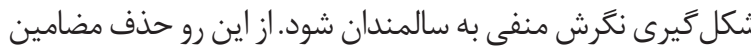

$$
\text { اين جنينى ضرورى است. }
$$

محدوديتهاى اين يزوهش عبارت بود از: در دسترسنبودن آرشيو 


\section{References}

[1] Heravi Karimoei M, Reje N, Foroughan M, Montazeri A. [Elderly abuse rates within family among members of senior social clubs in Tehran (Persian)]. Iranian Journal of Ageing. 2012; 6(4):37-50.

[2] Mohebbi L, Zahednejad S, Javadi Pour S, Saki A. [Domestic elder abuse in rural area of Dezful, Iran and its relation with their quality of life (Persian)]. Iranian Journal of Ageing. 2016; 10(4):50-9.

[3] Lee Burke J. Young children's attitudes and perceptions of older adults. The International Journal of Aging and Human Development. 1982; 14(3):205-22. [DOI:10.2190/4J7N-RG79-HJQR-FLDN]

[4] Asayesh H, Qorbani M, Parvaresh Masoud M, Rahmani Anarki $\mathrm{H}$, Ansari H, Mansourian M, et al. [General practitioner attitude toward elders: Using Kogan's attitudes questionnaire (Persian)] Iranian Journal of Diabetes and Metabolism. 2014; 13(6):479-86.

[5] Sanagoo A, Bazyar A, Chehrehgosha M, Gharanjic S, Noroozi M, Pakravan far S, et al. [People Attitude toward Elderly in Golestan Province, 2009 (Persian)]. Journal of Research Development in Nursing \& Midwifery. 2012; 8(2):24-9.

[6] Riahi F, Izadi-mazidi M, Khajedin N, Norouzi S. [Does education of geriatric medicine effect on the medical students' attitude toward elderlies and their care? (Persian)]. Iranian Journal of Medical Education. 2014; 14(7):651-2.

[7] Purfarzad Z, Ghamari zadre Z, Farmahini farahani M, Ghorbani M. [Teachers and student nurses' attitudes towards caring for older adults in Arak, 2012 (Persian)]. Journal of Clinical Nursing and Midwifery. 2014; 3(2):46-56.

[8] Hamadanizadeh F, Mtahedyan Tabrizi E, Sarhangi F, Zighaymat F. [Nurses' attitude care of old patients (Persian)]. Kowsar Medical Journal. 2008; 13(3):253-8.

[9] Barrett AE, Von Rohr C. Gendered perceptions of aging: An examination of college students. The International Journal of $\mathrm{Ag}$ ing and Human Development. 2008; 67(4):359-86. [DOI:10.2190/ AG.67.4.d]

[10] Pitcher D. Adopted children and their grandparents: Views from three generations. Adoption \& Fostering. 2009; 33(1):56-67. [DOI:10.1177/030857590903300106]

[11] Marzouk R., Mansory C. [Qualitative content analysis of elementary textbooks based on gender orientation (Persian)] Women in Development \& Politics Magazine. 2016; 13(4):469-85. [DOI:10.22059/jwdp.2015.58131]

[12] Dnaowski J. The portrayal of older characters in popular children's books: A content analysis from 2000 to 2010 [MA thesis] Provo: Brigham Young University; 2011. 


$$
\begin{aligned}
& \text { يبيوست ا. صفحه كدگذارى شخصيت سالمند }
\end{aligned}
$$

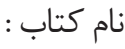

$$
\begin{aligned}
& \text { عنوان درس : } \\
& \text { سال انتشار : n n } \\
& \text { نام شخصيت : } \\
& \text { سن تقويمى : n }
\end{aligned}
$$

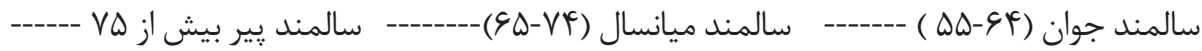

$$
\begin{aligned}
& \text { جنس: مرد ------- }
\end{aligned}
$$

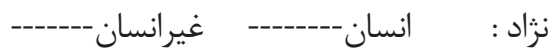

$$
\begin{aligned}
& \text { نقش شخصيت: كلى -------------- جزئى }
\end{aligned}
$$

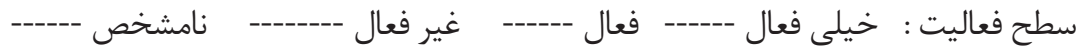

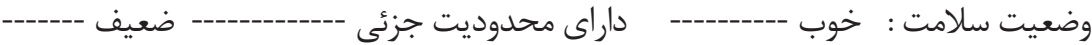

$$
\begin{aligned}
& \text { نقش اوليه: شوهر / زن --------- والدين ------- مادربزرى و يدربزرى ------ دوست ------ همكار ------ رئيس ------ آدم }
\end{aligned}
$$

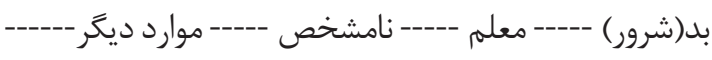

$$
\begin{aligned}
& \text { خصوصيات جسمانى : }
\end{aligned}
$$

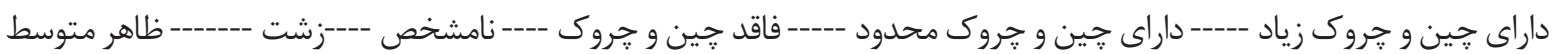

$$
\begin{aligned}
& \text { موى سفيد يا خاكسترى ---- تاحدى خاكسترى -----موى سياه /بور ----- نامشخص ------ } \\
& \text { تاس يا بى مو -----" يرمو ----نامشخص --" } \\
& \text { داراى موى صورت ( ريش يا سبيل ) ----- سفيد يا خاكسترى ------ مرتب ------ زوليده -----" }
\end{aligned}
$$

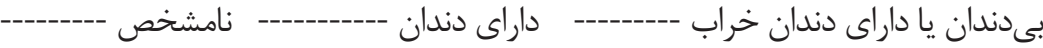

$$
\begin{aligned}
& \text { عينكى /داراى عينك تهاستكانى ----- سمعك -------- عضلات افتاده (مانند سينه آويزان)- } \\
& \text { قوز بيش از حد ------ استفاده از وسايل كمكى جسمانى ------ وسايل كمكى ديخر - - } \\
& \text { خصوصيات شخصيتى (روان شناختى) : } \\
& \text { ارزيابى كلى (براساس توصيف فيزيكى و شخصيتى): }
\end{aligned}
$$

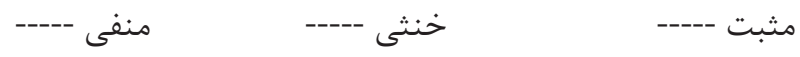


证 